\title{
Produção do cuidado e produção pedagógica: integração de cenários do sistema de saúde no Brasil
}

Túlio Batista Franco ${ }^{1}$

FRANCO, T.B. Healthcare production and pedagogical output: integration of healthcare system settings in Brazil. Interface - Comunic., Saúde, Educ., v.11, n.23, p.427-38, set/dez 2007.

Throughout the development of Brazilian public health system, considerable educational investments have been made in this sector. However, healthcare managers and workers find that the investments in educational programs have not led to changes in healthcare practices. Assuming that education can be a tool for change, this article suggests that teaching practices should provide guidance for those involved in providing care. Thus, they should take into account not only cognition, but subjective elements as well. This paper discloses Brasilian public health system management and its continuing education flows, establishing the focus of micromanagement for thinking about the context in which the many healthcare production settings are based, treating them as pedagogic production units where it would be possible to carry out educational methodologies linked to a general ideal of continuing healthcare education.

KEY WORDS: Healthcare. Continuing education. Health management. Subjectivity. Health system.

Em toda a história de construção do Sistema único de Saúde (SUS) há um razoável investimento na educação para o setor. No entanto, gestores e trabalhadores da saúde constatam que o investimento em programas educacionais não tem se convertido em mudança das práticas de cuidado. Partindo do pressuposto de que educação pode ser dispositivo de mudança, sugere-se que práticas pedagógicas direcionem a produção de sujeitos implicados com a produção do cuidado. Assim, propõe-se trabalhar, além da cognição, o campo das subjetivações. Este trabalho revela a gestão do suS e seus fluxos de educação permanente, constituindo o foco da "microgestão" para pensar no contexto sobre o qual se estruturam os diversos cenários de produção do cuidado, tratando-os como unidades de produção pedagógica, onde seria possível desenvolver metodologias educacionais vinculadas a uma idéia geral de educação permanente em saúde.

PALAVRAS-CHAVE: Produção do cuidado. Educação permanente. Gestão da saúde. Subjetividade. Sistema de saúde.

${ }^{1}$ Psicólogo; doutor em Saúde Coletiva; professor, departamento de Planejamento em Saúde, Instituto de Saúde da Comunidade, Universidade Federal Fluminense. Niterói, RJ. <tuliofranco@uol.com.br> 


\section{A gestão do suS como cenário diversificado de aprendizagem}

A educação na saúde tem sido defendida como uma prática corriqueira $e$ tem acompanhado o desenvolvimento do Sus, desde que este vem impondose por conquista popular e com o estatuto legal de reforma na organização da assistência à saúde. Embora haja grande investimento em educação, desde que se instituíram os princípios da reforma sanitária brasileira ou, mesmo antes da concepção de SUS, no bojo das lutas por universalidade, eqüidade $e$ integralidade da atenção, tem sido freqüente, na atualidade, nas conversas entre gestores e trabalhadores da área da saúde, a constatação de que, embora tenham sido despendidos grandes recursos e esforços em processos educacionais, seus impactos nos serviços não têm sido notados.

\begin{abstract}
o que se observou, no Brasil, foi o investimento recente em processos de formação posteriores à graduação ou à inserção nos postos de trabalho do Sistema de Saúde, não se instituindo um processo de mudança na formação que trouxesse a humanização, o acolhimento, a responsabilização para com o usuário das ações e serviços de saúde e o desenvolvimento de projetos de produção de autonomia no cuidado e na produção da vida como objetos de aprendizagem e montagem dos perfis de trabalho individual e coletivo. (Ceccim \& Ferla, 2003, p.212)
\end{abstract}

Algumas questões se colocam, desde sempre, por exemplo: por que, apesar de todo esforço em educação, na maioria das vezes as práticas assistenciais permanecem as mesmas, estruturadas por um processo de trabalho que opera com base em relações hierárquicas, os atendimentos continuam sumários e os trabalhadores abrigam-se no seu pequeno espaço de saberfazer, demonstrando grande dificuldade de interagir e conformar uma prática multiprofissional? Por que persiste, nos serviços de saúde, um processo de trabalho fragmentado, nos moldes tayloristas, com saberes que se isolam uns dos outros, onde há dificuldade de interação entre membros de uma mesma equipe, sobretudo, sob os valores e a cultura de uma clínica que tem, por referência, o velho modelo (flexneriano ${ }^{2}$ ), que sobrevive aos inúmeros apelos feitos nas diversas estratégias de educação (capacitações, revisões/atualizações etc.) dos trabalhadores da saúde?

Algumas respostas podem ser encontradas no percurso de estruturação da reforma sanitária brasileira. As políticas educacionais implementadas trouxeram uma idéia de processos de gestão excessivamente normativos, seja por uma herança impregnada nas subjetividades individuais e sociabilidades coletivas do planejamento e organização dos processos de trabalho, seja pela construção do SUS em um momento em que o protagonismo de grupos "sujeito" no ambiente organizacional era visto como algo não esperado $e$ não desejado pelas esferas de mando no interior das organizações e, muitas vezes, antagônico a elas. Iniciativas próprias, criação e inventividade no ambiente de trabalho eram considerados movimentos de resistência, bem como questionadores de uma desejável direção central da estrutura. Esse ambiente organizacional traz o imaginário de que a cadeia de mando do sistema de saúde ocupa o lugar do "saber" e este deve ser repassado para o
2 O chamado modelo flexneriano refere-se ao modelo de ensino médico implementado a partir do Relatório Flexner (EUA-1910), que sugeria uma formação que tivesse como eixo " $a$

necessidade de enlaçar o ensino com a investigação nas ciências biomédicas", decorrendo disso um modelo de prática médica centrada no corpo anátomofisiológico e tendo como principal referência o hospital (Nogueira, 1994, p.92-3). 
nível da produção, que supostamente não tem o conhecimento necessário para operar os processos disparados a partir da sua direção. Há um senso comum de não reconhecimento do conhecimento gerado com base nas vivências cotidianas na atividade de trabalho. A idéia geral de insuficiência dos trabalhadores, colocando-os como grupo "sujeitado" aos processos pensados por uma instância diretiva, gerou propostas educacionais tais como as embutidas na idéia da "educação continuada", onde a continuidade da "transferência de conhecimento" é necessária para suprir uma formação suposta como deficitária para os serviços de saúde. Metodologias educacionais implementadas com esse viés transformaram-se em verdadeiras máquinas de captura das subjetividades e anulação da capacidade criativa. $\mathrm{O}$ não-reconhecimento de um saber gerado a partir "da ponta" leva à formação de sujeitos heterônomos (grupos sujeitados em lugar de grupos sujeito) e é a isso que os trabalhadores ficam reduzidos, submetidos a uma "pedagogia da dependência".

No entanto, a aposta de que a educação serve a uma proposta de mudança dos serviços de saúde continua válida e atual, motivando a ação de milhares de trabalhadores, gestores e usuários do SUS. Constatamos, na questão, um paradoxo importante que se apresenta como um poderoso "ruído" nas políticas de educação para o setor da saúde, qual seja: de um lado, muitos investimentos institucionais historicamente disparados a partir do Ministério da Saúde, que efetivamente possibilita-nos notar o desejo de operar processos educacionais eficazes no atributo de transferir tecnologias de cuidado aos trabalhadores do SUS; $e$, de outro lado, baixo impacto desses mesmos programas de educação para o setor da saúde nos processos produtivos, isto é, na prática cotidiana de produção do cuidado. Tomamos o paradoxo citado como nosso "analisador" do problema da educação na saúde, isto é, como "aquilo que permite revelar a estrutura da organização, provocá-la, forçá-la a falar" (Lourau, 1996, p.284), e entendemos que compreendê-lo é imperativo para avançar no processo de mudança do sus.

Confirmando isso, experiências inovadoras de mudanças em sistemas e inovadoras em sistemas e serviços de saúde, pode-se consultar, por exemplo, Acolhimento: uma reconfiguração do processo de trabalho em saúde usuário-centrada (Malta et al., 1998); o acolhimento e os processos de trabalho em saúde: o caso de Betim/MG (Franco et al., 1999) e Acolher Chapecó: uma experiência de mudança do modelo tecnoassistencial com base no processo de trabalho (Franco et al., 2004), traçadores do acolhimento em unidades de produção de saúde, arrolados na bibliografia deste trabalho. serviços de saúde, que têm como base a reorganização do processo de trabalho ${ }^{3}$, têm demonstrado que a ação dos coletivos de trabalhadores em uma nova forma de produção do cuidado, cria nos mesmos um modo novo de significar o mundo do trabalho na saúde. Ao mesmo tempo em que produzem o cuidado, os trabalhadores produzem a si mesmos como sujeitos. Trabalho, ensino e aprendizagem misturam-se nos cenários de produção da saúde como processos de cognição e subjetivação e acontecem simultaneamente como expressão da realidade. Verificamos que, paralela à linha de produção do cuidado, há uma linha de produção pedagógica na estrutura organizacional do sus.

As linhas de produção do cuidado e pedagógica vão desde a atividade de pesquisa na área, a instituição de conceitos inovadores e práticas educacionais variadas, até sua base coletiva ou individual de operadores das práticas cuidadoras - os trabalhadores e usuários dos serviços de saúde. Tudo isto conta com o apoio de inúmeros órgãos formadores que colaboram com o sistema de saúde brasileiro. Os diversos atores sociais e políticos 
implicados com a construção do sus e embalados pelo ideário de transformação social constitutivo do histórico movimento sanitário e reivindicando-se como herdeiros do mesmo, produzem diversas propostas educacionais para a saúde que trazem, no seu enunciado, a idéia de educar com o objetivo de produzir sujeitos capazes de protagonizar mudanças nos serviços de saúde. A intenção das propostas é organizar a ação, direcionando-a para mudanças no nível organizacional, técnico-assistencial e nas relações em equipe, bem como nas formas de acolher e responsabilizarse pelo usuário. Provocar mudanças em algum sentido é o que guia o esforço pedagógico que se deve empreender atualmente.

O primeiro pressuposto, de onde partimos, é o de que a educação não se apresenta como um objetivo em si mesma, ou seja, sempre educamos para um desejo. Assim, entendemos os processos educacionais como dispositivos, tal como nos é ofertado esse conceito pelas correntes institucionalistas, onde "dispositivo" é "uma montagem ou artifício produtor de inovações que gera acontecimentos e devires, atualiza virtualidades e inventa o novo radical' (Baremblitt, 2002, p.135). O segundo pressuposto é o da educação como instituição, que opera a partir do humano, isto é, mobiliza sujeitos que trazem como elementos constitutivos do seu ser uma história de vida, uma origem sociocultural, saberes constituídos ao longo da sua formação $e$ vivências no trabalho em saúde, isto é, toda a complexidade do viver que forma uma certa subjetividade e coloca em ação, no mundo, uma forma singular. Um terceiro pressuposto é o de que, na educação, o trabalho é, em grande medida, relacional e, tal como na saúde, é "trabalho vivo em ato" (Merhy, 1997), tendo os trabalhadores da educação um grande autogoverno do seu processo de trabalho, o que permite disponibilizá-lo por inteiro aos seus "usuários".

Ao mencionarmos que é possível a educação operar no mundo das relações de ensino/aprendizagem como dispositivo, sugerimos que a ação pedagógica dispare processos de subjetivação, associados aos de cognição. A aposta que se faz é a de que os processos educacionais possam contribuir na produção de sujeitos, entendidos como coletivos com capacidade de intervir na realidade com o objetivo de transformá-la. Ora, um requisito importante para o protagonismo de um sujeito é a capacidade de auto-análise, isto é, "apropriação por parte dos coletivos autogestionários, de um saber acerca de si mesmos, suas necessidades, desejos, demandas, problemas, soluções e limites" (Baremblitt, 2002, p.139). Grupos que seriam capazes de "falar por si”. É nesse cenário que a idéia de reorganizar os processos de trabalho $e$ constituir um novo modo de produção da saúde, com base em princípios humanitários e de solidariedade, comparece como um objetivo a ser permanentemente perseguido, o processo instituinte que traz, no seu enunciado, o novo em potencial. O trabalhador de saúde opera a sua dimensão cognitiva, a de ser trabalhador dotado de plena capacidade técnica de intervir sobre problemas de saúde e opera, também, uma dimensão subjetiva, a de ser para si e o outro, conferindo alteridade nos atos de cuidado, onde o outro está sempre presente como sujeito na ação de produzir o cuidado.

Reconhecemos a existência de duas grandes dimensões no campo da 
educação, como vimos dizendo até aqui: uma primeira da cognição, que é dada pela capacidade de transferir e produzir conhecimento técnico em saúde, aplicado aos seus processos produtivos, dentro de uma certa organização do trabalho; e uma segunda, da subjetivação, que deve ser dada pela capacidade que têm certas pedagogias de promover mudanças na subjetividade.

De que forma processos de subjetivação podem ser verificados nas práticas cotidianas dos serviços de saúde? Para melhor compreender a questão, imaginemos um profissional fazendo uma anamnese e utilizando, para isso, um roteiro pré-organizado pela direção do estabelecimento de saúde. Ele pode fazer a anamnese em pouco tempo, de forma burocrática, dando pouco espaço para os atos de escuta e fala, centrando sua atividade no roteiro previamente estruturado. De outra forma, pode fazê-lo tendo o roteiro como guia, mas interagindo com o usuário, permitindo um espaço comum de trocas, intercessor. Segundo Merhy (2002, p.51), esse termo que designa

o que se produz nas relações entre sujeitos, no espaço das suas interseções, que é um produto que existe para os dois em ato e não tem existência sem o momento da relação em processo, e na qual os inter se colocam como instituintes na busca de novos processos, mesmo um em relação ao outro.

Diz Merhy que se abre, entre profissional e usuário, um "espaço intercessor", isto é, a relação mútua entre esses é ao mesmo tempo lugar de construção comum, no caso, do cuidado em saúde. O que faz com que o trabalhador aja de uma forma ou de outra é a sua subjetividade, estruturada com base na sua história de vida, das suas experiências, dos valores que adquiriu e que vão determinar uma certa forma de analisar e intervir sobre o mundo do trabalho em saúde. Contribui para isso sua implicação com o objeto, isto é, o problema de saúde do usuário com o qual se relaciona. A subjetividade e a implicação não aparecem nos manuais de ensino e aprendizagem, mas está presente em todo processo assistencial, de produção pedagógica e da saúde.

Entendemos que os processos educacionais só terão eficácia se conseguirem, junto com os processos de cognição, operar mudanças também nas subjetividades dos trabalhadores. Experiências nesse sentido têm sido observadas. Por exemplo, a Residência Integrada em Saúde, implantada pela Secretaria Estadual da Saúde do Rio Grande do Sul, em 2002 (Ceccim \& Ferla, 2003); e, no âmbito da educação permanente em saúde, a experiência da Secretaria Municipal da Saúde de Aracaju, analisada por Santos (2005) e Santana (2005). Além dessas experiências "locais", pode-se citar o esforço que se fez para disparar uma política nacional de educação $e$ desenvolvimento para o SUS a partir do Departamento de Gestão da Educação na Saúde, pelo Ministério da Saúde, durante a gestão 2003/2005.

Sobre a Educação Permanente em Saúde, refere Ceccim (2005, p.161)

a identificação Educação Permanente em Saúde está carregando, então, a definição pedagógica para o processo educativo que coloca o cotidiano 
do trabalho - ou da formação - em saúde em análise, que se permeabiliza pelas relações concretas que operam realidades e que possibilita construir espaços coletivos para a reflexão $e$ avaliação de sentido dos atos produzidos no cotidiano. A Educação Permanente em Saúde, ao mesmo tempo em que disputa pela atualização cotidiana das práticas, segundo os mais recentes aportes teóricos, metodológicos, científicos e tecnológicos disponíveis, insere-se em uma necessária construção de relações e processos que vão do interior das equipes em atuação conjunta, implicando seus agentes -, às práticas organizacionais, - implicando a instituição e/ou o setor da saúde -, e às práticas interinstitucionias e/ou intersetoriais, - implicando as políticas nas quais se inscrevem os atos de saúde.

A subjetividade é uma produção sociohistórica assumindo, portanto, um caráter dinâmico. É "o conjunto das condições que torna possível que instâncias individuais e/ou coletivas estejam em posição de emergir como território existencial auto-referencial, em adjacência ou em relação de delimitação com uma alteridade ela mesma subjetiva" (Guattari, 1992, p.19). Ela se estrutura nuclearmente no desejo, que se forma nos processos primários e é seu principal elemento. O desejo é, também, a energia que impulsiona o agir sobre o mundo. A mudança nesse núcleo é o que se chama de processo de subjetivação, capaz de alterar a intencionalidade sob a qual as pessoas atuam sobre o mundo da vida. A subjetividade pode sofrer processos de mudança ao longo do tempo ou ser levada a isso. No trabalho em saúde, ela pode se estruturar sob o ideal flexneriano de entendimento da clínica $e$ concentrar toda a capacidade de um trabalhador de lidar com problemas de saúde em intervenções no corpo anátomo-fisiológico; por outro lado, ela pode formar-se com base nos ideais e representações simbólicas que compreendem que o processo saúde-doença se dá a partir de múltiplos fenômenos, que são sociais, ambientais, clínicos ou subjetivos e demarcam, assim, um modo de agir diferenciado, que diz respeito ao sujeito que se apresenta com necessidades de cuidados a sua saúde. Lidar com a subjetividade é algo extremamente complexo e mais difícil é mudá-la, ou seja, criar processos de subjetivação capazes de produzir impacto no modo como cada um interpreta e atua sobre o socius. Isto é possível a partir das vivências, do experimento da vida, em processos que criam a exposição das pessoas e que, ao mesmo tempo, as afetam no seu modo de pensar, ser e agir sobre a realidade. Algo parecido com a Pedagogia do Fator de Exposição, conceito desenvolvido na III Fase do Projeto de Avaliação do Ensino Médico, encetado pela Comissão Interinstitucional Nacional de Avaliação do Ensino Médico (Cinaem) e apresentado no Relatório da Cinaem: Preparando a transformação da educação médica brasileira, citado em Santos (2005, p.106):

os fatores de exposição são objetos - recortes da realidade vivenciada, modos de ver e de delimitar um determinado campo da organização da vida, com existência real, natureza própria e sempre em produção, para os quais podemos dispor de um conjunto de saberes e tecnologias que nos permitem compreender, significar e intervir. 
Para Santos (2005, p.106), um dos autores desse relatório, a aposta que se fez no processo de implementação do Sus na cidade de Aracaju, durante sua gestão como secretário municipal de saúde, foi a de tomá-lo como "espaço de produção social de fatores de exposição". O autor nos fala muito objetivamente de processos de educação na saúde centrados no experimento e nas vivências do cotidiano do trabalho, isto é, uma metodologia que opera processos de cognição e, ao mesmo tempo, de subjetivação, pois dispara

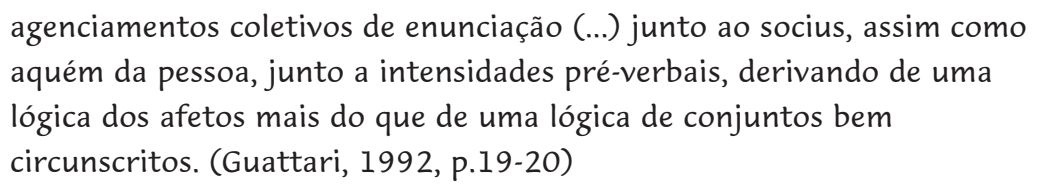

Para provocar processos de subjetivação, a educação permanente na saúde deve implicar os sujeitos com seu próprio processo de trabalho, colocandose, conforme Merhy (2005, p.174),

\begin{abstract}
diante do desafio de pensar uma nova pedagogia - que usufrua todas as que têm implicado com a construção de sujeitos autodeterminados $e$ comprometidos sociohistoricamente com a construção da vida e sua defesa, individual e coletiva - que se veja como amarrada a intervenção que coloca, no centro do processo pedagógico, a implicação ético-política do trabalhador no seu agir em ato, produzindo o cuidado em saúde, no plano individual e coletivo, em si e em equipe.
\end{abstract}

\title{
A gestão do sus e seus fluxos de educação permanente em saúde
}

O sus, pela dimensão e amplitude que tem, a capilaridade social e a diversidade tecnológica presente nas práticas dos trabalhadores, aparece na arena dos processos educacionais de saúde como um lugar privilegiado para o ensino e aprendizagem, especialmente os lugares de produção da saúde, o "chão de fábrica" do SUS, lugar rico de ação criativa dos trabalhadores e usuários. Educar "no" e "para o" trabalho é o pressuposto da proposta de Educação Permanente em Saúde. No SuS, os lugares de produção de cuidado são, ao mesmo tempo, cenários de produção pedagógica, pois concentram as vivências do cotidiano, o encontro criativo entre trabalhadores e usuários. É, como nos diz Deleuze, citando sua implicação com a leitura de Nietzsche: "ele dá um gosto perverso...; o gosto para cada um de dizer coisas simples em nome próprio, de falar por afetos, intensidades, experiências, experimentações" (Deleuze, 1992, p.15). Nas Unidades de Produção do Cuidado, onde se processam os encontros entre trabalhadores e usuários, é possível observar fenômenos menos relacionados ao cognoscitivo e mais vinculados ao campo dos agenciamentos de subjetividade.

A rede que constitui a gestão do SUS opera com forte transversalidade, em especial, quando opera por "linhas de produção do cuidado integral" sobre as quais trabalhadores e usuários buscam satisfazer as necessidades de saúde. Para melhor visualizar essa rede entrecruzada por vetores que agem 
fazendo a relação entre os diversos lugares de produção, propomos um diagrama interpretativo:

Diagrama da gestão do SUS e seus fluxos de Educação Permanente em Saúde para a produção pedagógica do cuidado

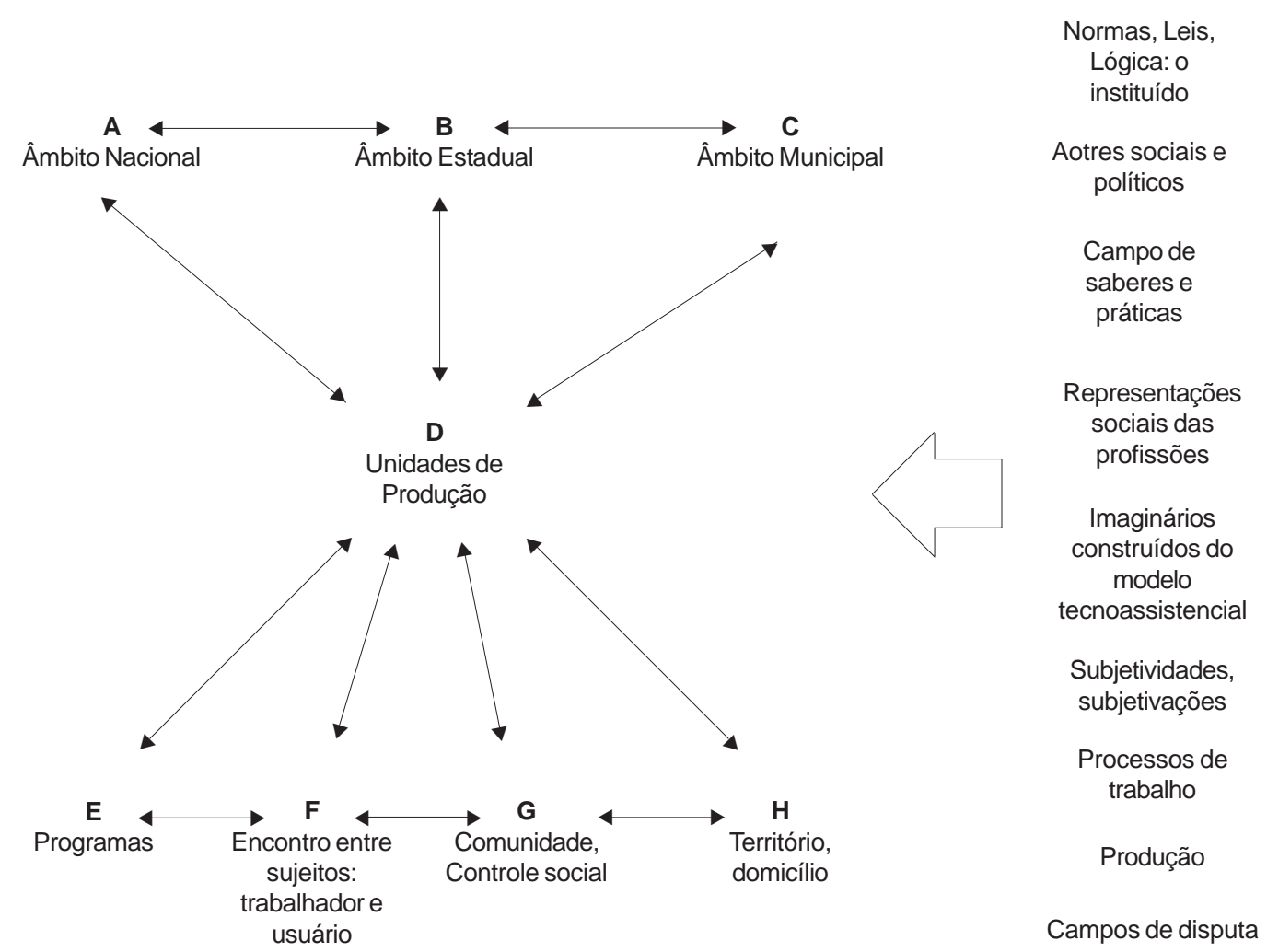

Este diagrama encontra-se desenhado na forma simétrica, como recurso didático e de efeito demonstrativo. Na realidade, deve ser considerado como absolutamente assimétrico, ou seja, as posições dos cenários mudam com a dinâmica dos acontecimentos que os afetam; os vetores que indicam os fluxos não têm a mesma freqüência e podem ter intensidades diferentes. Há uma tensão permanente entre os diversos cenários, visto que operam em rede e essa relação tensa provoca deslocamentos dos fluxos conectivos que assumem um efeito dinâmico sobre esse estado. Essas tensões e os fluxos agregam elementos de uma certa produção, que é social, política, técnica $e$ subjetiva, às políticas de saúde e educacionais, dependente da ação dos sujeitos/grupos-sujeito na micropolítica que opera nesses mesmos cenários. 
O diagrama representa diversos lugares de gestão, espaços de microgestão e produção do cuidado no interior do SUS, compondo os fluxos conectivos da rede. A microgestão se expressa na regulação da ação cotidiana dos trabalhadores, que é dada pelo instituído como padrão de conduta técnica, ética, política e subjetiva, socialmente produzida, a ser assumida diante do usuário e seu problema de saúde. A norma pode estar escrita como em um protocolo ou, simplesmente, se expressar como lógica que atravessa as relações de trabalho. Como o processo de trabalho em saúde é dependente de trabalho vivo em ato, caracterizando-se como autogovernável, inferimos que a microgestão é um espaço onde os trabalhadores fazem a gestão de si mesmos e do seu processo de trabalho, compondo práticas autogestionárias do trabalho em saúde ou, por outro lado, sofrendo processos de captura por normativas instituídas sobre o seu processo de trabalho. Há, entre os trabalhadores, um fluxo contínuo de saberes e fazeres que se traduzem por atos de fala e práticas no ambiente micro-organizacional, compondo cenários relacionais de alta intensidade.

Nessa estrutura, organiza-se a gestão do SUS como capacidade de governo, definido, aqui, como a alta direção do sus e das Secretarias de Saúde, assim como espaços de gestão local, que configuram uma instância intermediária de gerenciamento do governo geral do SUS, mas, sobretudo, há um espaço ainda pouco explorado, que diz respeito à microgestão que opera fortemente na determinação do modo de produção do cuidado à saúde. São cenários com forte potencial autogestionário, dada a natureza do trabalho em saúde, centrada no "trabalho vivo em ato permanentemente, um pouco à semelhança do trabalho em educação" (Merhy, 2002, p.48) e que, por isso mesmo, confere ao trabalhador uma alta liberdade de ação sobre o seu processo de trabalho. Há inúmeros campos temáticos que atravessam os cenários de produção da saúde e fazem a transversalidade, criando tensões sobre essa rede, o que torna os cenários vigorosos no sentido da criação de possibilidades de intervenção nos problemas de saúde e educação. É, ao mesmo tempo, uma arena de disputas de projetos, no âmbito intermediário do gerenciamento, que obriga a processos de pactuação entre os diversos atores implicados com a saúde, sobre as formas de gestão desse aparato assistencial, bem como de cuidado aos usuários.

A idéia geral de tratar a educação como dispositivo contribui para compreender sua função estratégica na mudança das práticas de cuidado, sobretudo, na transição tecnológica na saúde (Franco, 2003). Posições essas, desde sempre, reivindicadas por aqueles que lutam por um serviço de saúde centrado nas necessidades dos usuários (Malta et al., 1998). Uma prática educacional - como a que se propõe aqui - se coloca na perspectiva libertária, com sentido claro de imprimir transformações nos sujeitos e no SUS. Os cenários de produção do cuidado, como cenários de produção pedagógica, ressignificam a educação na saúde e colocam-na para além da relação ensino-aprendizagem, mas no âmbito dos agenciamentos de cognição e subjetivação, com o sentido de criar grupos-sujeito capazes de assumir para si o protagonismo, sob certa intencionalidade, que determina o desenvolvimento do sus. 


\section{Conclusões}

A questão aqui colocada, de que as Unidades de Produção do Cuidado são, ao mesmo tempo, Unidades de Produção Pedagógica, associa-se à idéia de uma "pedagogia em ato", constitutiva dos protagonismos que compõem o "quadrilátero da formação para a área da saúde, ensino-gestão setorialpráticas de atenção-controle social”, sugerido por Ceccim \& Feuerwerker (2004, p.41-65). Essa é uma diretriz sobre a qual se fazem novas apostas de superação dos entraves à mudança na saúde, uma aposta que acredita que a mudança necessária passa, indiscutivelmente, pela constituição de novos sujeitos/grupos-sujeito e de outras subjetividades, despertadas/convocadas no interior dos serviços de saúde.

Outro aspecto relevante é tratar o trabalho como nuclear à ação pedagógica, quando se fala de educação permanente na saúde. Isto deve ser visto na perspectiva de que a ação produtiva é duplamente transformadora, onde ao mesmo tempo em que o trabalhador produz os atos de cuidado, mudando a realidade, produz a si mesmo como sujeito. "A subjetividade é produzida por agenciamentos coletivos de enunciação" (Guattari \& Rolnik, 1999, p.31). A atividade de trabalho na saúde produz enunciados durante todo o seu processo. Pela sua natureza relacional, a dinâmica do trabalho vivo em ato traz a possibilidade de ter o mundo da saúde em transformação e, sobretudo, a implicação dos sujeitos com a atividade produtiva. Tudo isso traz, em si. a potência da mudança dos trabalhadores e dos usuários. A produção pedagógica ocorre pari passu à produção do cuidado, sendo constitutivos da mesma os processos de cognição e formação de novas subjetividades.

Identificamos o caráter imanente entre produção de cuidado e produção pedagógica, quando se refere à educação permanente na saúde. Isso significa que um está no outro, isto é, o trabalho está na pedagogia e esta na atividade laboral, e eles só têm a potência de produzir educação permanente quando há essa imanência. A vivência, ou melhor, a experimentação que possibilita o afetamento dos sujeitos do processo educacional só ocorre se houver, ao mesmo tempo, trabalho e educação ocorrendo juntos, agindo transversalmente nos cenários do sus.

Processos de mudança no SUS, especialmente nas formas de produção do cuidado, com base na reorganização do processo de trabalho, devem ter como pressuposto a educação permanente dos trabalhadores da saúde. Ela aparece como a metodologia eficaz para agregar novo conhecimento às equipes e torná-las protagonistas dos processos produtivos na saúde. Tudo isso tem como pano de fundo a micropolítica dos processos de trabalho que operam nos diversos cenários do SUS, sejam aqueles mais relacionados à esfera da gestão ou aqueles mais relacionados ao âmbito assistencial. 


\section{Referências}

BAREMBLITT, G. Compêndio de análise institucional. Belo Horizonte: Instituto Félix Guattari, 2002.

CECCIM, R.B. Educação permanente em saúde: desafio ambicioso e necessário. Interface - Comunic., Saúde, Educ., v.9, n.16, p.161-8, 2005.

CECCIM, R.B.; FEUERWERKER, L. O quadrilátero da formação para a área da saúde: ensino, gestão, atenção e controle social. Physis - Rev. Saúde Coletiva, v.14, n.1, p.41-65, 2004.

CECCIM, R.B.; FERLA, A.A. Residência integrada em saúde: uma resposta da formação e desenvolvimento profissional para a montagem do projeto de integralidade da atenção à saúde. In: PINHEIRO, R.; MATTOS, R. (Orgs.). Construção da integralidade: cotidiano, saberes e práticas em saúde. Rio de Janeiro: IMS-Uerj/Abrasco, 2003. p.211-26.

DELEUZE, G. Conversações. São Paulo: Editora 34, 1992.

FRANCO, T.B. Processos de trabalho e transição tecnológica na saúde: um olhar a partir do sistema cartão nacional de saúde. 2003. Tese (Doutorado) - Faculdade de Ciências Médicas, Universidade Estadual de Campinas, Campinas.

FRANCO, T.B.; PERES, M.A.; FOSCHIERA, M.A.; PANIZZI, M. (Orgs.). Acolher Chapecó: uma experiência de mudança do modelo tecnoassistencial com base no processo de trabalho. São Paulo: Hucitec, 2004.

FRANCO, T.B.; BUENO, W.S.; MERHY, E.E. O acolhimento e os processos de trabalho em saúde: o caso de Betim/MG. Cad. Saúde Pública, v.15, n.2, 345-53, 1999.

GUATTARI, F. Caosmose. São Paulo: Editora 34, 1992.

GUATTARI, F.; ROLNIK, S. Micropolítica: cartografias do desejo. Petrópolis: Vozes, 1999.

LOURAU, R. A análise institucional. Petrópolis: Vozes, 1996.

MALTA, D.C.; FERREIRA, L.M.; REIS, A.T.; MERHY, E.E. Acolhimento: uma reconfiguração do processo de trabalho em saúde usuário-centrada. In: CAMPOS, C.R.; MALTA, D.C.; REIS, A.T.; SANTOS, A.F.; MERHY, E.E. (Orgs.). Sistema Único de Saúde em Belo Horizonte. São Paulo: Xamã, 1998. p.121-42. MERHY, E.E. Em busca do tempo perdido. In: MERHY, E.E.; ONOCKO, R. (Orgs.). Agir em saúde: um desafio para o público. São Paulo: Hucitec, 1997. p.71-112.

O desafio que a educação permanente tem em si: a pedagogia da implicação. Interface Comunic., Saúde, Educ., v.9, n.16, p.172-4, 2005.

Saúde: a cartografia do trabalho vivo. São Paulo: Hucitec, 2002.

NOGUEIRA, R.P. Perspectivas da qualidade em saúde. Rio de Janeiro: Qualitymark Editora, 1994.

SANTANA, A.D. Sobre o desafio de qualificar os trabalhadores de saúde: estudo do processo de construção da política de educação permanente do município de Aracajú, SE. 2005. Dissertação (Mestrado) - Instituto de Medicina Social, Universidade Estadual do Rio de Janeiro, Rio de Janeiro.

SANTOS, R.C. Implantação e implementação do SUS em Aracajú a partir do modelo técnico assistencial Saúde Todo Dia. 2005. Tese (Doutorado) - Faculdade de Ciências Médicas, Universidade Estadual de Campinas, Campinas. 
FRANCO, T.B.

FRANCO, T.B. Producción del cuidado y producción pedagógica: integración de los marcos del sistema de salud en Brasil. Interface - Comunic., Saúde, Educ., v.11, n.23, p.427-38, set/dez 2007.

En toda la historia de la construcción del sistema de salud brasileño hay una razonable inversión en educación para el sector. No obstante, gestores y trabajadores de salud constatan que la inversión en programas educacionales no se ha convertido en cambios de las prácticas de cuidado. Considerando que educación puede ser dispositivo para cambios, se sugiere que las prácticas pedagógicas se orienten hacia la producción de sujetos comprometidos con la producción del cuidado. Se propone pues trabajar, además de la cognición, el campo de las subjetividades. Este trabajo revela la gestión del sistema y sus flujos de educación permanente, constituyendo el foco de la "micro-gestión" para pensar en el contexto sobre el cual se estructuran los distintos marcos de producción del cuidado, tratándolos como Unidades de Producción Pedagógica donde sería posible desarrollar metodologías de educación vinculadas a una idea de educación permanente en salud.

PALABRAS CLAVE: Producción del cuidado. Educación permanente. Gestión de la salud. Subjetividad. Sistema de salud. 